\title{
Os projetos educativos das Ruínas Engenho São Jorge dos Erasmos: discussões preliminares sobre o patrimônio
}

Rodrigo Christofoletti*

André Muller de Mello**

\section{Resumo}

O Monumento Nacional Ruínas Engenho São Jorge dos Erasmos, constitui um dos mais antigos testemunhos arquitetônicos quinhentistas brasileiros ainda existentes. Um dos primeiros engenhos de açúcar a ser construído, o Engenho dos Erasmos tem sido palco de relevantes estudos em diversas áreas do saber, o que incentivou a abertura do bem cultural ao público, sobretudo aos alunos de ensino fundamental das escolas públicas estaduais e municipais da Baixada Santista. Pretende-se, neste breve artigo, discutir alguns elementos norteadores desta proposta pedagógica que completou cinco anos de funcionamento em agosto de 2009, focando a discussão em três pontos básicos: a) o processo de construção e democratização de saberes, a partir de uma proposta interdisciplinar; b) os mecanismos de investigação e diálogo resultantes de questões formuladas pela própria comunidade e c) a gestão participativa do bem cultural em questão, sinalizando para as relações de proximidade dos visitantes com seu próprio passado.

Palavras-chave: Preservação arquitetônica. Patrimônio cultural, Santos, SP, Brasil. Educação ambiental.

\section{Abstract}

The National Monument Ruins Mill São Jorge dos Erasmos, located in Santos County - São Paulo State, constitutes one of the oldest Brazilian sixteenth century architectural testimonies that still exist. One of the first sugar engines to be built, the Engenho dos Erasmos has been stage of important studies in several areas, what stimulated the opening of this cultural asset to the public, mainly for the students of fundamental education of the state and municipal public schools of the Baixada Santista. It is intended in this brief paper to discuss some guide elements 
of this pedagogical proposal that completed four years in past August, whose discussion is emphasized in three basic points: a) the process of construction and democratization of knowledge, from a interdiscipline proposal, b) the investigation and dialogue mechanisms that are results of questions formulated by the community, and c) the participatory management for the proximity relations of the visitors with their own past.

Key words: Architectural preservation. Cultural heritage, Santos, SP, Brazil. Environment education.

\title{
1 A Interdisciplinaridade e a preservação como metas de ação
}

\author{
(...) não há mais barulho nas moendas do Engenho! \\ não há mais do que um pão de açúcar... \\ a moenda quebrou, a civilização mudou, \\ virou mineral fluido diluído no doce azedo das lembranças \\ Entre as chibatas e as garapas, as rapaduras e as ditaduras do solo \\ restou apenas o sonho de um mundo adocicado."
} (José Lins do Rego)

A materialidade de uma conquista pode muitas vezes ser medida em números. Em outros momentos em mudanças de hábito. Mas, em ocasiões especiais, em transformações efetivas de cultura. Com relação à preservação de bens culturais essas três possibilidades (dentre outras mais) sinalizam uma permanente busca por nossa identidade. Nesse sentido, olhar para trás, tal como afirmava Mario de Andrade, "é se permitir mudar algo que se via irresoluto. É salvaguardar o quase irrecuperável" (BRUMANA, 2006, p. 545). Incentivados por esta máxima mariana e convictos de que caminhamos por essa seara (olhar para trás como exercício diário de ressignificação de nossa função enquanto educadores) relataremos neste artigo um balanço crítico dos últimos cinco anos de atuação em um dos bens culturais mais antigos ainda preservados em território nacional. Trata-se do monumento nacional Ruínas Engenho São Jorge dos Erasmos, hoje, uma base avançada de pesquisa, cultura e extensão da USP. Localizada no município de Santos, remonta às primeiras incursões dos europeus em solo brasileiro. Estas 
ruínas de quase quinhentos anos guardam informações valiosas sobre os primórdios da arquitetura colonial brasileira, além de registrarem partes de episódios que culminaram no primeiro empreendimento capitalista brasileiro a se destacar, em princípios do século 16.

\subsection{Ruínas de longa história - um conto por ser contado}

Do ponto de vista histórico a expedição de Martim Afonso de Souza a São Vicente, em 1532, pode ser considerada o ponto de partida para a indústria açucareira no Brasil. A construção deste engenho de açúcar, ponto central de nossa análise, é o corolário deste empreendimento que vai rapidamente mudar de mãos. Martim Afonso de Souza, donatário da Capitania de São Vicente, considerado pioneiro na colonização do Brasil, foi responsável pelo lançamento das bases da ocupação da região, criando uma infraestrutura que permitiu a fixação dos portugueses no território. Além de doar sesmarias e construir fortalezas, introduziu o cultivo da cana-de-açúcar na capitania, levando à construção do Engenho, provavelmente no ano de 1534.

O outrora denominado Engenho do Governador, posteriormente "dos Erasmos", quando adquirido pela família de Erasmos Schetz de Antuérpia, tornou-se na época de sua edificação um dos três engenhos construídos em território vicentino. Os outros dois, das famílias Adorno e Reys, não nos deixaram nenhum registro de cultura material. O Engenho dos Erasmos tornou-se propriedade dos Schetz por volta de 1540. Ainda no primeiro quartel do século 16, Erasmos Schetz aparece como fundador de uma empresa em Leipzig. Seus negócios na Alemanha envolviam uma casa bancária, seguros marítimos e minas de cobre e prata. Em seguida, suas atividades comerciais estenderam-se até Antuérpia, Bruxelas e Amsterdã. Os Schetz distribuíam seus produtos por toda a Europa e tinham ligações de caráter comercial com italianos, holandeses, franceses, portugueses, alemães, além da Companhia de Jesus.

Sem dúvida, o período de apogeu do Engenho São Jorge dos Erasmos como manufatura açucareira foi sob a direção da família Schetz. Os documentos da época colonial registram que esses negociantes flamengos fizeram várias tentativas de vender sua propriedade no Brasil entre 1593 e 1612 . O brilhante 
levantamento sucessório dos proprietários do engenho realizado pela professora Maria Cecília França Lourenço (1) nos dá a dimensão do quanto aprofundadas eram tais relações entre o capital, a terra e as famílias capitalistas da recém criada capitania. (LOURENÇO, 2006, p. 20).

O Engenho funcionou, segundo o historiador Paul Meurs, até o século 18. E, ao longo desse período, produziu cana para exportação, além de rapadura e aguardente para consumo interno em ambas as vilas (Santos e S. Vicente) no século 18. Ao longo desse século, porém, podemos constatar a decadência da propriedade. Para a produção de açúcar e derivados, além da fábrica propriamente dita, o Engenho comportava unidades administrativas e residenciais, inclusive (sic) dependências dos escravos. A parca documentação escrita (em grande maioria em flamenco arcaico, espanhol e português do século 16, acervo este a ser traduzido) certamente poderá revelar um manancial riquíssimo de informações a serem decifradas.

Das poucas informações que dispomos sobre a trajetória mais recente deste empreendimento (com exceção dos achados arqueológicos realizados entre as décadas de 1990 e 2000, coordenados pelos professores Margarida Andreatta, hoje no Museu Paulista, e José Luiz de Moraes, do Museu de Arqueologia e Etnologia da USP), consta que em 1943, os terrenos com as ruínas foram adquiridos por Otávio Ribeiro de Araújo, que loteou a propriedade e doou o Engenho São Jorge dos Erasmos à Faculdade de Filosofia, Letras e Ciências Humanas da USP, no ano de 1958. No mesmo ano, Luís Saia, chefe do $4^{\circ}$ Distrito da Diretoria do Patrimônio Histórico e Artístico Nacional, órgão federal, relatou ao presidente da Comissão Especial do Engenho São Jorge dos Erasmos que realizou prospecção e definiu o partido arquitetônico como de "modelo açoriano, tipo real e movido à água" (SAIA, 1958).

No entanto, é importante salientar que o engenho é o único exemplar que restou em território brasileiro, como testemunho dos tempos em que a indústria açucareira era o produto essencial nos negócios e na economia do incipiente território. De 1958 até a década de 1990 ocorreram poucas ações efetivas de preservação, mas, em princípios dos anos 2000 uma nova compreensão dotou as 
Ruínas de uma equipe que passou a propor programas educacionais/preservacionistas em larga escala e para múltiplos públicos. É um pouco desta história que este balanço crítico pretende apresentar.

\subsection{As Ruínas como lugar de memória}

O uso qualificado de bens culturais e a sua conseqüente preservação constituemse em grandes desafios para governos e comunidades neste início de século. As estratégias culturais de salvaguarda dos patrimônios foram cada vez mais desafiadas pelo jogo plural de uma nova perspectiva histórica. Em nossos dias a reconstituição sistemática de modos de vida de uma época anterior, através de espaços e trocas sociais converte o campo da memória em teatro preferencial de uma busca objetiva de conhecimento.

A discussão sobre a relevância e o papel da memória nos dias atuais sinaliza a escolha, por parte considerável da historiografia, de eleger como foco de suas preocupações os chamados lugares da memória, que nascem e vivem da constatação de não haver memória espontânea. Torna-se, portanto, urgente criar arquivos, manter aniversários, organizar celebrações, requalificar espaços justamente porque estas operações não são naturais. Pois, como afirma Pierre Nora, "sem vigilância comemorativa, a história depressa os varreria". São eles, os lugares da memória, portanto, bastiões sobre os quais se escora toda a escolha do lembrar. (Nora, 1993, p. 13)

A memória está estratificada no lugar. Em consonância, lugares de memória projetam histórias regadas à cumplicidade, significações, afetividade, pertencimento. (Nora, 1993, p. 13). Ela se enraíza no concreto, no espaço, no gesto, na imagem, no objeto, projetados a um passado vivo e revivido que ainda marca presença e reforça os traços identitários do lugar. Por isso, entendemos as Ruínas Engenho como um lugar de memórias, construto coletivo de memórias coletivas.

Paralelamente a esta exploração de novos lugares memoriais o consenso sobre a conservação dos bens culturais (em acordo com as Cartas Patrimoniais internacionais) foi abalado pela diversidade e contradição das representações 
mnemônicas existentes nas sociedades; e, por isso, a organização e o tratamento destas formas de memórias coletivas influenciaram uma crítica da própria ideia de patrimônio.

Não se trata mais de saber como ele se conserva, mas sim de aprender as funções sociais das memórias dentro da metamorfose das sociedades. Em decorrência disto, Henri Pierre Jeudy mostra o quanto "a interação ente a memória e o patrimônio ainda gera uma teatralização dos valores de uma época" (JEUDY, 2005, p. 9). Para este autor a reconstituição do modus vivendi de uma época anterior, através dos espaços e trocas sociais transforma o campo da memória em teatro de um conhecimento objetivo. Coloca-se então um paradoxo sobre o qual nem a memória nem o ato preservacionista têm controle: estabelecese um duelo entre o poder destruidor das memórias silenciadas e o poder petrificador e conservacionista das culturas.

O foco sobre este atributo destruidor da memória ganha então relevância porque muitas das testemunhas dos diversos espaços/lugares têm idades avançadas, o que indica uma diferenciada postura no resguarde de suas ações. Isto denota que a memória sempre se qualifica de acordo com o significado que ela atribui aos fatos, lembranças e lugares. No caso específico das lembranças elegidas sobre as Ruínas Engenho São Jorge dos Erasmos, estas, apresentam-se necessariamente como elementos problematizadores do presente e não como informações cristalizadoras de um passado. Por isso a confluência de detalhes que, sob o foco das memórias parecem sempre tão desconexos. Estabelece-se assim, o que Marc Augé chama de lugares em que se sobressai uma antropologia do próximo. Segundo o sociólogo francês, o dispositivo espacial é o elemento que exprime a identidade de um grupo, isto porque este lugar tem pelo menos três características comuns. Se pretende identitário, relacional e histórico.

De outro prisma, refletir sobre como dado bem cultural precisa ser apresentado para se comunicar frente a distintos públicos, também se mostra fundamental. Isto é, a maneira como as Ruínas são apreendidas pelas pessoas que as conhecem (não como algo reificado, petrificado pela ação do tempo, mas como espaço qualificado, produtor de conhecimento e arregimentador de memórias plurais) é a 
condição primordial para o não esquecimento deste bem. Este é um dos papeis desempenhados pelas Ruínas Engenho São Jorge dos Erasmos: lugar em que pessoas encontram proximidade identitária e que por isso congrega memórias diversas, coletivas e individuais.

A ruína pode por um lado evocar o passado glorioso e a caducidade de todas as coisas, ser objeto de reflexão histórico-filosófica; por outro lado pode dar lugar a um sentimento sutilmente crepuscular; pode ser uma ruína clamorosa, eloqüente, com uma massa obstrutiva ou, pelo contrário, um efêmero bastidor visual, um frio contraste, uma ironia irrisória. Essa vitalidade da ruína exclusivamente interpretativa, subjetiva e antropológica, por isso qualificada. (CARENA, 1984, p. 107)

A qualificação destes lugares corresponderia então à formalização pensada por De Certeau, para quem, "os lugares de atuação seguem uma ordem segundo a qual elementos são distribuídos em relação de coexistência. Coexistem dentro de um lugar comum a todos" (DE CERTEAU, 1994, p. 9) O lugar de atuação dessas ações e memórias coletivas pode ser o mais diverso possível. Exemplo disto é a interação criada a partir de uma comunidade e as memórias que esta produz sobre um dado lugar. Nesta interação, as pessoas, suas memórias e as transformações ocorridas no espaço através do qual criaram identidade fundemse num plasma que congrega passado e presente de maneira pouco nítida. O que se viu e o que se vê misturam-se diante dos olhares plurais. Exemplo acabado de espaço que tem esta característica são as Ruínas Engenho São Jorge dos Erasmos.

\subsection{Programas educacionais e abrangência preservacionista}

Nos últimos cinco anos o Monumento Nacional Ruínas Engenho São Jorge dos Erasmos tem se notabilizado por ser um bem cultural diferenciado de seus congêneres, devido ao seu caráter eminentemente educacional. Os programas educacionais implementados pela equipe de educadores vêm solidificando a intenção primordial do Plano Gestor, que busca ampliar, divulgar e produzir conhecimento, de uma perspectiva coletiva. $O$ ano de 2004 marcou definitivamente a vocação das Ruínas como campo aberto para as interpretações interdisciplinares e consolidou a sua presença no conjunto dos mais atuantes e conscientes domínios públicos voltados para a educação formal/não formal do 
estado de São Paulo. Para a nossa equipe de educadores, Educação se faz em movimento, e no gerúndio, como bem nos lembra o educador Paulo Freire, para quem a forma indicativa no fazer educação está fadada a reproduzir uma educação bancária, hermética e não libertadora, pois já nasce pronta, préfabricada. Fazer educação no gerúndio significa aprender com a continuidade, superar os eventuais percalços que possam existir, e mais que isso, crescer com as diferenças, pelo simples fato de justamente o diferente possibilitar ao indivíduo a identificação.

Nenhuma transformação real se efetiva por alquimia, por toque de mágica. Por isso essa mudança só é possível mediante o movimento, a ação efetiva, pois a educação em que acreditamos é uma construção coletiva, pela ação do coletivo e para o coletivo. Cada qual com suas funções, seus espaços de atuação definidos. As Ruínas cumprem bem este papel de espaço plural das coletividades, de suas construções e transformações. A transformação de uma criança que, ao vislumbrar pela primeira vez o espaço das Ruínas, imagina estar diante apenas de pedras amorfas e sem vida. Ao final da visita, porém, modifica suas interpretações por verificar, se estimulada em sua criatividade, que tais pedras falam, contam histórias, explicam fatos, agitam curiosidades e nos deixam ainda mais dúvidas do que antes de conhecê-las.

É desta modificação que nos aproximamos, protagonizada pelo visitante enquanto vê, sente e muda sua maneira de perceber o entorno. A educação em movimento se faz pelo gerúndio, mas deve concordar com a forma que for possível: só não pode ser pretérita (passada, esquecida no toque do tempo), pois senão não é educação, é saudade. Neste sentido, entre os milhares de visitantes nestes quatro anos de trabalho, muitos dos participantes de nossas visitas reflexivas (2) voltaram a visitar as Ruínas ao menos mais uma vez nos fins de semana, e mesmo nos períodos de férias, confirmando a premissa de que a pessoa termina por apropriar-se de determinado espaço ao qual se sente pertencente.

Desde meados de 2005 foram combinados esforços para a construção de uma sede, denominada Base Avançada de Cultura e Extensão, constituída pela edificação de um auditório, sala para múltiplo uso, administração, seminários, 
ateliê, reserva técnica e laboratório que substantivaria a premissa revelada neste artigo. A primeira etapa da obra, concluída em finais de 2007 (cuja inauguração ocorreu em Junho de 2008 com o I Seminário de Educação em Bens Culturais: Desafios e Trocas, além do lançamento de publicação comemorativa) contemplou as condições necessárias para a manutenção e o funcionamento das significativas atividades desenvolvidas no espaço. A segunda etapa ficou pronta em finais de 2009, com inauguração no mês de novembro do mesmo ano.

Ao contrário da práxis daqueles partidários do saber centralizado, mantidos por gerações em algumas instituições de reconhecimento renomado, a equipe do Monumento Nacional Ruína Engenho São Jorge dos Erasmos vem buscando reverter a consciência de que o conhecimento de qualidade é algo restrito àqueles de melhor condição sócio-econômica. Visando mudar o foco desta realidade tão nociva à construção de um país menos desigual, a Base Avançada se mostra como uma possibilidade viável de democratização, alocada para servir com qualidade todo visitante destas Ruínas. Levando-se em consideração que se trata de uma das regiões da Baixada Santista menos assistidas econômica e socialmente, dada sua característica geograficamente periférica, a Zona Noroeste, região em que se situam as Ruínas, terá a possibilidade de usufruir de um centro coletivo de cultura, lazer e aprendizado. A população em geral (vinculada ou não a uma instituição de ensino) ganha, com a entrega da Base Avançada, um consistente apoio na produção de ações afirmativas de caráter educacional.

\section{Ruínas Engenho: laboratório de conhecimentos integrados}

Hoje, parece-nos lugar-comum entender o espaço das Ruínas Engenho São Jorge dos Erasmos como um imenso laboratório em que cultura, educação e lazer se encontram. A trajetória recente das Ruínas como lugar de sistemática exploração histórico-social começou a se destacar em meados de 1996, período inicial de um programa de escavações arqueológicas que se prolongou por alguns anos. (3) Se o projeto arqueológico foi o mote de intervenção da comunidade científica junto às Ruínas até 2002, permanecendo o Monumento Nacional praticamente restrito às visitações de pesquisadores, a partir de 2004 o foco migrou para uma preocupação em aproximar a comunidade do bem em questão, 
qualificando sua utilização por meio de programas pedagógico-educacionais que incentivem o protagonismo e o sentimento de pertencimento do visitante. Era necessário apresentar à comunidade o que havia sobrevivido de uma história de quase cinco séculos. As Ruínas haviam se tornado palco de diversas descobertas, laboratório inestimável para uma série ilimitada de pesquisas. Chegara a hora de abrir os portões das Ruínas Engenho para que a comunidade pudesse fruir esse bem cultural.

Os trabalhos realizados junto às Ruínas buscaram, a partir de então, aprimorar o caráter e a vocação educacional do espaço em questão, realizando diversos projetos que visassem aproximar a história, a cultura e a memória do lugar, concorrendo para que a comunidade pudesse, a partir de então, sentir-se corresponsável pela preservação desse monumento nacional.(4)

A visão que a comunidade tem hoje das Ruínas é muito diferente da compartilhada há pouco menos de uma década. O Monumento Nacional Ruínas Engenho São Jorge dos Erasmos finalmente encontra seu lugar de direito na construção do mapa afetivo da comunidade. As lendas assombrosas que povoavam o imaginário da comunidade deram lugar a histórias de participação, comunhão e descobertas, antes jamais imaginadas. A falta de informação criou uma aura de lugar proibido para as Ruínas, hoje dissipada com a interação comunitária, foco primordial dos projetos educacionais desenvolvidos no local. As escolas e famílias encontram nesse espaço uma equação que resulta da aproximação entre: educação, entretenimento pedagógico e senso de comunidade, elementos fundamentais na construção da identidade contemporânea e da busca de registros e significados dessas Ruínas.

Em consonância com essa busca, a pedagogia dos projetos em desenvolvimento visa apresentar as Ruínas a partir de uma monitoria, aqui denominada "visita dialogada" que tem como foco preocupações sócio-histórico-ambientais. A iniciativa prevê a estruturação de um roteiro de visita (previamente discutido com o professor) (5) no qual busca-se estabelecer o contato entre o visitante e os diversos significados e conteúdos das Ruínas, tanto por meio de exposições quanto através de jogos, dinâmicas e atividades. A visita deixa de ser um evento 
isolado e as técnicas de interpretação histórico/ambiental previstas pela visita dialogada fundem-se ao conhecimento individual do visitante, o que torna a visita algo prazeroso. O resultado é um roteiro elaborado para dosar estrutura e espontaneidade servindo tanto aos objetivos afetivos de ensino quanto aos cognitivos propriamente ditos, construindo assim a noção de resistência e permanência.

Nesse sentido, tal proposta pedagógica pretende tratar os elementos formadores do complexo das Ruínas Engenho como algo que possibilite ao visitante dois princípios básicos: a) estimular a construção de sua identidade, incentivando o sentimento de pertencimento deste em relação ao bem cultural; b) sinalizar para este visitante a necessidade de se preservar a sensibilidade coletiva, sem desprezar a identidade individual, despertando nele o senso crítico e a sensibilidade ética. Apresentaremos a seguir um sumário de três dos oito projetos em atividade atualmente nas Ruínas. (6) A escolha dos três projetos se dá, na medida em que juntos totalizam cerca de $80 \%$ da visitação anual do bem.

\subsection{O projeto Laboratório de Memórias}

Um dos primeiros projetos elaborados a partir da formatação da Plataforma Sophia visou registrar fragmentos de memória de moradores da comunidade circunvizinha às Ruínas Engenho São Jorge dos Erasmos e que tiveram como cenário de lembranças o terreno do bem cultural propriamente dito. Assim nasceu - Laboratório de Memórias, leque transdisciplinar disposto a registrar as memórias e as reminiscências de antigos moradores vizinhos ao engenho. A partir de relatos de pessoas que em algum momento, tiveram contato com as Ruínas Engenho São Jorge dos Erasmos, buscou-se reconstituir parte de suas memórias levando em consideração um elemento significativo: o que a comunidade registrou com relação a este bem cultural a partir de suas percepções individuais cindidas pela junção da memória coletiva.

Lembranças como tempos de criança, brincadeiras no espaço do engenho, notícias da ocupação e utilização do local dentre outras memórias fizeram parte do roteiro de questões elaborado conjuntamente com os depoentes. Valioso instrumento metodológico para a condução dos depoimentos e posterior fomento 
de oficinas e atividades conjuntas, este roteiro norteou a parceria estabelecida entre os moradores da comunidade, os alunos universitários participantes do projeto e as escolas circunvizinhas ao bairro. Pois, foi da junção dos esforços desses três núcleos que se construiu uma diferenciada percepção de como os moradores desta localidade viam e vêem as Ruínas Engenho São Jorge dos Erasmos.

A zona Noroeste da cidade de Santos, local onde estão localizadas as Ruínas (7), iniciou sua urbanização a pouco menos de 40 anos. O fato de ter ocorrido um processo tardio de urbanização certamente colaborou para que muito de sua mata nativa e seus segredos arquitetônicos mais antigos permanecessem sumariamente preservados. Um dos bairros constituintes deste recente surto urbanístico é a Vila São Jorge. Erguida nos anos 1950 esta localidade foi testemunha da ocupação que, de certa forma, ajudou na conservação e preservação desse singular bem cultural brasileiro.

Se por um lado a urbanização acelerou a especulação imobiliária mudando a paisagem da região, (atualmente a Vila São Jorge ocupa uma área de $512 \mathrm{mil} \mathrm{m}^{2}$ com uma população de pouco mais de 50 mil habitantes), por outro a distância do centro da cidade e do fluxo de pessoas e transportes colaborou para que nestes últimos 50 anos o patrimônio histórico em questão permanecesse como há séculos atrás. A Vila São Jorge, que recebe este nome em homenagem ao santo padroeiro do Engenho e do curso d'água (hoje canalizado) que corta a região é atualmente uma valiosa comunidade no que tange aos potenciais memorialísticos sobre a história recente desta região e, sobretudo, da localidade onde estão situadas as Ruínas Engenho São Jorge dos Erasmos.

Após a década de 1950 a incorporação das Ruínas pela Universidade de São Paulo favoreceu ainda mais sua salvaguarda. Após uma sucessão de diversos proprietários e um longo período de quase esquecimento, foi a partir deste momento que sua importância como documento passou a ser reconhecida, cabendo a cada época vivificar as Ruínas com seus mais diletos valores. 0 projeto Laboratório de Memórias tornou-se um enriquecedor instrumento de conscientização sobre a importância do processo preservacionista, por parte dos 
moradores das adjacências. Foi visando preservar fragmentos desta memória que este projeto buscou dar voz aos relatos da comunidade, relevância às suas lembranças e visibilidade à iconografia remanescente.

Os primeiros resultados das entrevistas e das buscas por iconografia em posse dos moradores coincidiu com o estreitamento de laços institucionais entre o monumento nacional e o Projeto Historiando a Zona Noroeste, importante iniciativa do Fórum Social da Zona Noroeste, de várias secretarias da Prefeitura de Santos, entidades que atuam na região, além de moradores. Reunindo um acervo com mais de cem fotos que, compiladas em uma exposição itinerante, contam a história e o desenvolvimento da Zona Noroeste, este projeto assumiu a responsabilidade pela coleta de imagens e depoimentos dos moradores da localidade. O Laboratório de Memórias tornou-se parceiro do projeto contribuindo com documentos e imagens anteriormente colecionadas, além de inserir-se no roteiro de visitas elaborado pela Secretaria Municipal de Turismo. O bem cultural recebeu, enfim, a exposição itinerante em agosto de 2008, durante as comemorações de inauguração da Base Avançada de Cultura e Extensão Universitária, no próprio Órgão.

Partindo deste entendimento propôs-se identificar como a comunidade da Vila São Jorge viu e via as Ruínas São Jorge dos Erasmos (por meio de sua memória coletiva e da percepção que detêm sobre o bem cultural). Com isso, pudemos entender melhor a relação existente entre os moradores do bairro e este patrimônio. Objetivou-se assim, a partir de evidências orais e fotográficas, inventariar as informações disponíveis por esta comunidade sobre a localidade e o seu entorno. Fundamentais para o entendimento de sua história recente, as informações disponibilizadas por estes moradores nos auxiliaram no entendimento mais aprofundado sobre a ocupação e os condicionantes que fizeram deste bem algo destacável da paisagem semiurbanizada da região.

\subsection{O projeto VouVolto}

Para proteger é necessário conhecer e para conhecer é necessário educar. Este conceito sustenta a necessidade de se sensibilizar o poder público e a comunidade no sentido de garantir que a memória sobre o Engenho dos Erasmos 
permaneça como um elemento relevante da constituição identitária desta comunidade. A salvaguarda de um bem cultural deve ser estimulada por um interesse coletivo de apropriação e reconhecimento. Uma integração entre o coletivo, sua memória e o bem a ser protegido. É o caso específico do monumento nacional Ruínas Engenho São Jorge dos Erasmos, lugar por excelência de preocupações sobre a manutenção e preservação históricoambientais. O imperativo da preservação sensibilizou setores da sociedade (a universidade é um exemplo claro disso), tornando-se premente erigir na consciência de cada indivíduo a relevância da preservação cultural por meio de ação educativa. Ação a partir da qual o tripé (ação/preservação/identidade) poderá redimensionar a relação existente entre as sociedades e os testemunhos de seu passado e presente.

Projetos como o VouVolto, (carro chefe de nosso programa educativo e que tem como público alvo os estudantes do ensino fundamental das escolas estaduais e municipal da cidade de Santos) (8) buscou, por exemplo, estabelecer o diálogo sobre as plurais possibilidades de reconstituição de uma história que, junto com o emaranhado das memórias destes moradores precisa vir à luz das novas gerações. A qualificação do uso das Ruínas do Engenho passou, a partir da implantação deste projeto, a incentivar a investigação histórica e a compreensão dos condicionantes ambientais em que o Engenho se insere propondo discussões para os mais diversos públicos. Nesse sentido, passou-se a entender o Engenho São Jorge dos Erasmos a partir de três pontos: a) a partir de sua inserção na sociedade quinhentista brasileira; b) mediante as transformações da tecnologia do fabrico do açúcar, do qual é exemplo significativo; c) diante do processo de ocupação do espaço de produção e das relações sociais nele contidas.

Como afirma a historiadora Fernanda Maria Felipe dos Anjos:

[...] Essas questões, que envolvem os aspectos sociais e econômicos da vida em um engenho entre os séculos XVI e XIX, passam pelo projeto português de dominação e exploração das áreas coloniais e se concretizam na materialização das ações (na cultura material) e nas transformações que os homens operaram no meio ambiente em que viveram (como ocuparam e organizaram a sua sobrevivência nesse mesmo espaço). (ANJOS, 1998, p. 65) 
É mediante a apreensão dos aspectos citados acima que se buscou a realização de um projeto pedagógico que viabilizasse a compreensão não só da história do Engenho dos Erasmos (hoje em ruínas) e da constituição ambiental na qual ele se insere, mas também de como tal engenho testemunhou profundas transformações no modo de ver e viver da sociedade brasileira, ao longo dos séculos. Para tanto, como recomenda o geógrafo Aziz Ab'Sáber, tal projeto precisaria, antes de tudo, levar em conta preocupações interdisciplinares envolvendo, principalmente, variadas interpretações sobre o Engenho. O geógrafo advogava (isso em 1999) (9) ainda a necessidade de se adequar projetos que abrangessem as partes alta e baixa da planta das ruínas buscando uma ampla compreensão dos elementos referentes ao complexo histórico/ambiental/arquitetônico lá existente. Desse desejo, e da sensibilidade de Maria Cecília França Lourenço, à época Diretora do bem, nasceu o projeto VouVolto para o ensino fundamental.

Nasceu dessa confluência de desejos a proposta do projeto de educação sóciohistórico-ambiental voltado ao público das escolas estaduais do ensino fundamental. Uma das vantagens de trabalhar com estudantes é que eles são um grande grupo organizado e podem servir como instrumento para alcançar outros segmentos da comunidade. Como uma ilha no meio da aglomeração urbana da zona noroeste santista, as Ruínas sofreram pressões de toda ordem (econômicas, sociais, culturais e políticas) (10). O Projeto parte do pressuposto que a educação é o instrumento fundamental para minimizar tais pressões, debatendo e qualificando o discurso de apropriação do bem público.

A iniciativa previa a estruturação de um roteiro de visita com monitoria integrada (11) no qual se estabelecia o contato entre o visitante e os diversos significados e conteúdos das Ruínas, tanto por meio de exposições quanto através de jogos, dinâmicas e atividades. Um dos mais relevantes aspectos do Programa quanto ao seu grau de inovação foi a inclusão de uma etapa específica que antecede a visita às Ruínas do engenho pelos alunos. $O$ professor realiza uma visita prévia $e$ encontra subsídio técnico para elaborar o seu próprio Plano de Estudo. Em contato com o monumento, com os educadores do Programa e com material de 
apoio, o profissional do ensino possui então condições de conciliar os potenciais educacionais das Ruínas com as metas que constam do Plano de Curso da escola. A visita deixa de ser um evento isolado e as técnicas de interpretação do ambiente previstas pela monitoria fundem-se ao instrumento individual do professor, o que torna tal instrumento altamente idiossincrático. O resultado é um roteiro de visita elaborado para dosar estrutura e espontaneidade, indicando que as atividades serão executadas de forma consciente, particularmente no que se refere ao uso do tempo, servindo tanto aos objetivos afetivos de ensino (os mais importantes para o Programa) quanto aos objetivos cognitivos (que têm significativa relevância no Plano de Curso em andamento naquele ano letivo).

Em contato com esta premissa básica (educar para conhecer) a comunidade estimula-se a preservar, conscientizando-se da importância de seu papel na perenidade do bem cultural. Isto assegurou a não deturpação de seus significados históricos, uma vez que a conservação e preservação romperam as fronteiras limítrofes da cultura material para abranger a comunidade em que está inserido. Tais elementos sustentaram a relevância e a abrangência do projeto VouVolto.

\subsection{0 projeto I-Papo - Imaginário e práticas aproximativa do patrimônio}

Destinado também ao ensino fundamental, porém fruto de uma necessidade específica de atender as escolas mais distantes e os professores com dificuldades de acesso prévio ao monumento nacional, o I-Papo utiliza a pedagogia de projetos e inclui um conjunto de jogos, dinâmicas e atividades que visitam durante algumas semanas as escolas.

Inúmeras unidades de ensino ainda apresentavam determinadas dificuldades para vencer as distâncias e chegar até este espaço, ante uma série de fatores adversos como, por exemplo, a dificuldade em pagar o transporte. Tais dificuldades inviabilizam uma relação de proximidade com os conhecimentos disponíveis no bem cultural.

Para suprir esta demanda foi criado um projeto que busca alimentar e estimular o saber num processo conjunto de descobertas através das quais alunos e professores investiguem e formulem, mesmo à distância, porém com suporte dos 
educadores do Órgão, episódios, personagens, fatos e hipóteses constituintes da história deste lugar.

O I-PAPo nasce fruto deste contexto e corrobora, portanto, um desejo antigo da nossa equipe de educadores: viabilizar alternativas que façam verter das páginas da internet, do sitio eletrônico das Ruínas e de demais suportes pedagógicos o conhecimento que é, também, apreendido presencialmente. A visita continua sendo uma fase fundamental no programa de descobertas e de interiorização dos conhecimentos, mas deixa de ser condicional, insubstituível, passando a ser uma das etapas do processo de aprendizagem.

Desta vez a proposta pedagógica propõe que revisitemos o período em que o engenho foi construído para lembrarmo-nos do encontro de grupos étnicos e matrizes tão distintas, da intensificação do comércio ultramarino, das obras dos imortais renascentistas, das grandes invenções que revolucionaram a imagem que o homem medieval tinha do Universo. Trazendo temas geradores (ou "chaves de compreensão", como especificado na publicação do professor) o programa busca evocar ainda as transformações dos hábitos alimentares com o uso das especiarias, a migração dos vegetais e os avanços a respeito do conhecimento sobre os mares e as novas terras. Pretende-se concretizar um convite aos jovens para o estudo da biologia das florestas aqui presentes, da geografia descritiva desta singular paisagem, da revisão histórica das outras ciências da natureza como a matemática e a física, com suas divisões na contemporaneidade, da história do cosmo e do desenvolvimento da arte. Desta forma, sugere apreender o Monumento Nacional como ícone de uma era de transição e transformações, emblema de conquistas, empreendedorismo europeu, conflitos, devastação, miscigenação e mudanças de paradigmas ocorridos no início da era moderna.

O I-Papo possibilita a escolha de vários módulos independentes, incentivando diversidade de conteúdos e visitas por parte de um mesmo grupo. Um conjunto de atividades com as quais é possível aprofundar o tema do patrimônio e refletir sobre o público e o privado, tornando cada visitante um protagonista dos processos de apropriação do bem cultural. As ciências têm seu lugar assegurado, englobando desde medições (espaciais, por exemplo), cálculos (das relações 
entre distâncias e tempo) e identificações (de espécies animais e vegetais, de técnicas construtivas, de recursos naturais explorados, etc), quanto estudos sobre o passado e as inúmeras inovações tecnológicas em questão, em diferentes meios e suportes.

Ora objeto de estudo, ora cenário de estudo, o monumento nacional transformase em palco de leituras distintas através da metodologia de projetos e da educação continuada, possibilitando o surgimento de infinitas questões espontâneas e autênticas que poderão ser investigadas pelos próprios alunos à medida que retornam às Ruínas munidos do método científico. As respostas ou hipóteses propostas pelos alunos tendem a extrapolar o visível e o imediato, encontrando representação através do imaginário.

\section{Finalizando as premissas}

No caso da relação entre as Ruínas Engenho São Jorge dos Erasmos e a comunidade adjacente ao bem a conquista de uma aproximação mais efetiva e substantiva sinaliza uma clara transformação na cultura de visitar e preservar este local. O "olhar para trás" de Mario de Andrade referido no início deste artigo, permitiu a mudança do "algo que se via irresoluto". A presença da comunidade propiciou a saudável e participativa "salvaguarda do quase irrecuperável". Portanto, a máxima mariana nos conforta ao respaldar a nossa premissa: é para o coletivo e pelo coletivo que bens culturais como este precisam ser preservados. Com efeito, movimentos que busquem a manutenção das memórias dessa localidade tornam-se enriquecedores por valorizarem a troca e não simplesmente a transmissão de conhecimento. Em síntese, o local passou a servir como um espaço qualificado para experimentação, estudos e práticas conjuntas, além de cenário para eventos que promovam o intercâmbio entre os conhecimentos produzidos nas universidades e aquele empírico das comunidades. Por tudo isso, tais Ruínas representam hoje o fruto de décadas de ajustes e desejos que culminaram em 2010 com implementação de uma rede de sociabilidade que congrega diversas parcerias abrangendo um leque variado de instituições, Ongs, Associações de Bairro, universidades de todo o mundo e representantes do terceiro setor. Constitui-se, portanto, num centro de referência na democratização do saber. 
Isto posto, registra-se que esse monumento nacional se caracteriza como um dos poucos lugares ainda preservados a guardar em suas histórias de resistência e de sofrimento os germes do princípio do capitalismo no Brasil. Se, inicialmente, foi na brisa quente da Bahia que os europeus derramaram seus inebriados suores quando pela primeira vez chegaram às terras tropicais, foi nas extensões do litoral paulista que a identidade do cadinho miscigenado (europeus, africanos e nativos) deu feição ao que hoje chamamos Brasil. As Ruínas Engenho São Jorge dos Erasmos são marca inconteste dessa história. Por isso é preciso conhecê-lo e preservá-lo para as próximas gerações.

Este processo de modificação e ampliação constantes de nosso olhar sobre os monumentos culturais sedimentou a possibilidade de sua preservação a partir, sobretudo, de um conjunto de relações e memórias coletivizadas, nos permitindo enxergarmos relações interessantes entre bens culturais diversos. De maneira bastante abrangente os resultados alcançados ao longo dos últimos cinco anos reproduziram a união de forças em prol de uma meta bastante significativa: tornar as ruínas deste antigo engenho de açúcar um local de preservação, espaço público de fruição, aprendizado e identidade, respeitando suas capacidades e colaborando para que os esquecimentos do passado não reportem mais a negligência, o abandono e a perda de suas histórias. Pois, mesmo que a própria Universidade, em um inesperado surto de miopia democrática ou um mergulho cego em joguetes políticos internos, venha um dia a menosprezar o zelo com a memória, a semente da preservação deste bem cultural único, permanecerá germinando e tilintando como um aviso intermitente. Isso, graças aos passos dados na última década em direção à gestão participativa e amadurecida dos gestores, membros do Conselho Deliberativo e educadores, que se esforçaram em criar oportunidades para que a comunidade reencontre significados múltiplos nessas ruínas: sentimento condicional a qualquer sonho em longo prazo.

Pode-se concluir que os resultados alcançados nestes anos de atividades, superaram a necessidade da mecânica contagem de visitantes e se fortaleceu nas sólidas parcerias que nortearam e engendraram novos olhares para sua preservação. A estimativa para os próximos anos segue a linha ascendente dos 
programas que levam em consideração não apenas a busca de números capazes de solidificar sua existência perante a comunidade acadêmica, mas, sobretudo, considerando estarmos mais próximos de romper a maior e mais difícil resistência: a errônea ideia de que monumentos culturais como as Ruínas devem ser mantidos fora do alcance das pessoas. Reside aí um erro conceitual e uma de nossas maiores conquistas é a constatação de que este erro precisa ser corrigido para o usufruto e o bem de todos.

Paralelamente, é preciso considerar que tanto a educação como a preservação do patrimônio e da memória estão inscritas em territórios distintos como o político, o econômico e o social. Portanto, ensinar o respeito ao passado, mais do que a sua simples valorização, é contribuir para a formação de uma sociedade mais sensível e apta a construir um futuro menos predatório e descartável, menos submetido à lógica econômica de um mercado cada vez mais voltado para os jovens, seus hábitos e seus gostos (ou a volatilidade destes). É construir uma sociedade que respeite seus velhos como portadores de saberes e tradições que precisam e devem ser reinventados ou transmitidos, em sua integridade, às gerações futuras. Daí talvez se possa avaliar a importância da cultura e da educação em operar a invisível transformação de que tanto carecem os povos de países como o nosso. E nesse sentido, o processo educativo interdisciplinar será a pedra de toque que nos ensinará a repetir valores que se baseiam no respeito à diferença e valorização da diversidade, buscando com isso, "temperar" o sujeito como um ser preservacionista e crítico.

Para tanto, as Ruínas Engenho São Jorge dos Erasmos têm buscado estabelecer uma agenda que dê conta de responder às questões elencadas a seguir: a) valorizar a diversidade da base social na qual este patrimônio é constituído, reconhecendo, preservando e difundindo as referências culturais brasileiras em sua heterogeneidade e complexidade; b) permitir o acesso de todos aos direitos e benefícios gerados pela preservação deste patrimônio cultural, promovendo a apropriação simbólica e o uso sustentável dos seus recursos patrimoniais com o objetivo de contribuir para o desenvolvimento social e cultural do país; c) aquilatar seu acervo como fonte de conhecimento para o desenvolvimento das ações de preservação, desenvolvendo parcerias com a sociedade, com vistas a 
democratizar e ampliar a diversidade cultural do país. Todos esses elementos sinalizam para uma pluralidade de entendimentos que faz das Ruínas Engenho São Jorge dos Erasmos um lugar de memória e de ação histórica por natureza.

\section{Notas}

(1) Instrumento de busca imprescindível para o levantamento sucessório dos proprietários do Engenho, esta listagem serve de referência para quem pretende iniciar os estudos sobre o Engenho dos Erasmos. Caderno VouVolto, Listagem sucessória, 2006. Ver VouVolto, [2006] - Algumas fontes para estabelecimento de datas, [p. 23-36].

(2) Os visitantes são instigados de maneira sinestésica a se relacionarem com o espaço refletindo sobre as informações recebidas e interagindo com as mesmas, de maneira a se apropriarem dos saberes construídos coletivamente.

(3) Ver: Relatório do Projeto Arqueologia dos Erasmos, MAE-USP, 2003.

(4) As Ruínas ESJE são tombadas pelas três esferas: federal (1962), estadual (1973) e municipal (1990).

(5) Uma das etapas previstas objetiva a visita prévia do professor, na qual ele conhecerá o local, bem como os projetos em andamento e os potenciais educacionais que o espaço proporciona, envolvendo-o no planejamento das atividades de ensino-aprendizagem desenvolvidas antes, durante e após a visita propriamente dita.

(6) Em ordem de implantação: Plataforma Sophia (2004); Vou Volto (2004); Portas Abertas (2004); Laboratório de Memórias (2005); Território e Transformações (2006); I-Papo - Identidades e práticas aproximativas do patrimônio (2007); Eleja- voltado para o Ensino de Jovens e Adultos (2008) e Engrenagens - cujo foco é o ensino técnico (2008). Para saber detalhes acesse: www.usp.br/prc/engenho.

(7) Até finais do século XIX as Ruínas localizavam-se na cidade de São Vicente. Com as transformações urbanas ocorridas em princípios do século XX a delimitação espacial de ambos os municípios da ilha de $\mathrm{S}$. Vicente sofreu profundas mudanças ocasionado perda de território por parte de São Vicente. Para aprofundamentos desta questão consultar: Programa: Território e Transformações. Equipe de educadores da RESJE - USP, 2005.

(8) O ano de 2008 foi de muita comemoração por parte da equipe de educadores das Ruínas, pois a visitação ao bem foi incorporada no currículo escolar das escolas municipais de Santos como ponto de partida para o estudo de História do Brasil, a partir do $4^{\circ}$ ano escolar, antiga terceira série.

(9) Ver Aziz N. Ab'Sáber, Proposta de um parque no velho território dos Erasmos, Revista USP, 1999. Ver mapa do sitio no anexo e roteiro de visitas que prevê monitoria integrada em ambas as partes da planta do engenho. 
(10) De maneira geral, as pressões de âmbito político foram implementadas sob a chancela da crítica do suposto "abandono" das Ruínas. Tais críticas serviram de plataforma publicitária para alguns políticos favoráveis à implantação de outra destinação ao complexo das Ruínas, ignorando, muitas vezes, a manutenção e gestão desenvolvidas pela Universidade de São Paulo que previa um projeto de preservação e não restauração das dadas ruínas.

(11) A monitoria integrada utiliza instrumentos interpretativos visando aumentar a satisfação e o aproveitamento dos visitantes, manipulando até certo ponto o impacto sobre alguns sítios específicos, direcionando as atitudes e características de conduta sobre os mesmos (para melhor apreciação do ambiente), e visando tornar compreensível o papel da instituição que desempenha jurisdição sobre a área tombada. Além disso, a monitoria integrada visa tornar explícita a discussão interdisciplinar como conduta de atuação deste projeto.

\section{Referências bibliográficas}

AB'SÁBER, Aziz N. Proposta de um parque no velho território dos Erasmos. Revista USP, n. 41, p. 10-17, mar./abr./maio 1999.

ABREU, Regina; CHAGAS, Mário (Orgs.). Memória e patrimônio: ensaios contemporâneos. Rio de Janeiro: DP\&A, 2003.

ANJOS, Fernanda Maria Felipe dos. Engenho São Jorge dos Erasmos: uma abordagem interdisciplinar do documento na arqueologia histórica. Dissertação (Mestrado)-Faculdade de Filosofia, Letras e Ciências Humanas, Universidade de São Paulo, São Paulo, 1998.

AUGÉ, Marc. Não lugares. Introdução a uma antropologia da supermodernidade. São Paulo: Papirus, 1998.

BABELON, J. P.; CHASTEL, A. La notion de patrimoine. Paris: Liana Levi, 1994.

BRUMANA, Fernando Giobellina. Mario de Andrade y a Misión de Pesquisas Folklóricas (1938). Revista de Indias, n. 237, p. 545-572, 2006.

CAMARGO, Ana Maria de Almeida; BELLOTTO, Heloísa L. (Coords.). Dicionário de terminologia arquivística. São Paulo: AAB, 1996.

CARENA, Carlo. Ruína e Restauro. In: LE GOFF (Org.). Enciclopédia Einaudi, Porto: Imprensa Nacional Casa da Moeda, 1984. p.107-129.

CARTAS patrimoniais. Brasília: IPHAN, 2002.

CHOAY, François. A alegoria do patrimônio. São Paulo: Estação liberdade, 2001.

DE CERTEAU, Michel. A invenção do cotidiano. Tradução: Ephraim Ferreira Alves. Rio de Janeiro: Vozes, 1994. 
FONSECA, Maria Cecília Londres. O patrimônio em processo: trajetória da política federal de preservação no Brasil. Rio de Janeiro: UFRJ/IPHAN, 1997. 676 p.

FUNARI, Pedro Paulo Abreu; PELEGRINI, Sandra de Cássia Araújo. Patrimônio histórico e cultural. Rio de Janeiro: Jorge Zahar, 2006.

HALBWACHS, Maurice. A memória coletiva. São Paulo: Vozes, 1996.

I-PAPO: Programa Imaginário e Práticas Aproximativas do Patrimônio. Monumento Nacional Ruinas Engenho São Jorge dos Erasmos. São Paulo, SP: PRCEU/USP, 2007. 63 p.

JEUDY, Henri Pierre. Espelho das cidades. Rio de Janeiro: Casa da Palavra, 2005.

LE GOFF, Jaques. ENCICLOPÉDIA EINAUDI: [Monumento- Documento]. Porto: Imprensa Nacional/Casa da Moeda, 1994. v. 1.

LONDRES, Cecília. Celebrações e saberes da cultura popular: pesquisa, inventário, crítica, perspectivas. Rio de Janeiro: FUNARTE; IPHAN; CNFCP, 2004.

LOURENÇO, Maria Cecília França. Patrimônio e pranto. In: PLATAFORMA Sophia. Ruinas Engenho São Jorge dos Erasmos. São Paulo, SP: PRCEU/USP, 2006. p. 8-31.

Projeto Educacional VouVolto. Ruínas Engenho São Jorge dos Erasmos, Pró-Reitoria de Cultura e Extensão Universitária/USP, 2004.

MENESES, Ulpiano T. Bezerra de. Para que serve um museu histórico? In: Museu Paulista da USP. Como explorar um museu histórico. São Paulo: MP/USP, 1992. p. 3-5.

NORA, Pierre. Entre memória e história: a problemática dos lugares. Projeto História (PUC-SP), n. 10, p. 728, dez. 1993.

RELATÓRIO do Projeto Arqueologia dos Erasmos. São Paulo: MAE/USP, 2003.

RIEGEL, Alois. Le culte moderne des monuments: son essence et sa genèse. Paris: Seuil, 1984.

RUÍNAS Engenho São Jorge dos Erasmos. Disponível em: <htpp://www.usp.br/prc/engenho>.

SAIA, Luiz. Notas sobre o processo de restauração do Engenho dos Erasmos, 1958. Pasta Primeiros Processos. (1958-1963), s/n. Documentação do Arquivo Permanente do órgão - Ruínas Engenho São Jorge dos Erasmos, Pró-Reitoria de Cultura e Extensão Universitária da USP.

VOU Volto: Projeto Educacional para o Ensino Fundamental: [PRCEU-USP]. Ruínas Engenho São Jorge dos Erasmos, São Paulo, SP: PRCEU/USP, [2006]. 22 p. II. 


\section{Créditos}

*Educador da Universidade de São Paulo nas Ruínas Engenho São Jorge dos Erasmos e Doutorando em História Política e Bens Culturais pela Fundação Getulio Vargas - CPDOC. Leciona nos cursos de História e Direito da Universidade Católica de Santos Unisantos.

e-mail: rchristofoletti@usp.br

**Biólogo voltado à Biologia da Conservação, educador da Universidade de São Paulo nas Ruínas Engenho São Jorge dos Erasmos. Integra a equipe de professores responsáveis por projetos para o ensino médio do Centro Paula Souza. Leciona em escolas técnicas da Secretaria de Desenvolvimento do Estado de SP. e-mail: bioandre2002@yahoo.com.br 